\title{
O crítico como artista
}

Vera Lins

RESUMO: O texto trabalha dois escritores da virada do século XIX para o século XX, Gonzaga Duque e Nestor Victor, ambos críticos e ficcionistas. Seus textos são vistos como marcados por um pensamento que problematiza, colocando questões sobre a arte, a literatura e a crítica ainda cruciais hoje. Trabalham o ensaio como forma de crítica, que incorpora sensibilidade e intelecto. Subjetividades questionadoras, articulam cenas de pensamento no que se poderia chamar de um modernismo carioca na virada do século.

PALAVRAS-CHAVE: crítica, ficção, pensamento, virada do século.

ABSTRACT: This text examines two writers from the turn of the nineteenth to the twentieth century, Gonzaga Duque and Nestor Victor, both critics and fictionists. Their texts reveal problematizing thoughts, which raise questions about art, literature and criticism that are still crutial today. They employ the essay as a form of critique, which encompasses sensibility and intelect. Inquiring subjectivities articulate instances of thought into the modernism of turn-of-the-century Rio de Janeiro.

KEYWORDS: criticism, fiction, thought, turn of the century. 
Uma forma, uma figura, talvez sirvam para

pôr problemas, nunca para trazer conclusões.

Merleau-Ponty

Vou trabalhar aqui com dois críticos da virada do século xix para o xx, GD e NV. Ambos foram ligados ao movimento simbolista: Nestor Victor é conhecido como o amigo e editor de Cruz e Sousa, e Gonzaga Duque é nosso primeiro crítico de artes. E ambos são ficcionistas também, escrevem contos e romances. Quero mostrar como sua crítica é permeada por esse veio ficcional, o que os torna ensaístas fortes, que conseguem pensar o que é difícil de ser pensado, o que não se resolve facilmente, o paradoxal.

Os escritos sobre arte de Gonzaga Duque podem ser vistos como ensaios que colocam na própria forma questões estéticas como a da representação e questões da própria crítica. Escolhi dois textos de seu livro Contemporâneos, que podem ser lidos como reflexões sobre a inapreensibilidade do objeto da crítica e as limitações do juízo estético. Além de colocarem em questão a representação.

No texto sobre o Salão de 1904 o crítico se autoironiza, dizendo-se um rabiscador de crônicas, para afirmar logo de início, também com ironia, que os expositores são fracos - apenas habilidosos, não sabem interpretar:

Mas, se as notas, porventura justas, de um rabiscador de crônicas, habitualmente desajeitadas e pretensiosas, obtiverem atenção de alguém e da sua emissão se derivar conceito, direi que nesta exposição, como nos anteriores Salões, só encontro pintores de figuras e paisagistas, porque na maneira de interpretar os assuntos e de os fixar a igualdade é quase completa, com desconto das habilidades. ${ }^{1}$

Seu romance, Mocidade morta, conta os embates de um grupo de jovens artistas liderados por um crítico, alter ego seu, os insubmissos, contra a pintura acadêmica. Abre com uma cena em que na inauguração da pintura de batalha de um pintor oficial, Telésforo, os insubmissos o acolhem com vaias e risos.

1. DUQUe, Gonzaga. Contemporâneos. Rio de Janeiro: Typographia Benedicto de Souza, 1929. 
Outro artigo, "O Salão de 1905", é um texto de crítica singular na sua composição. $\mathrm{O}$ crítico entra nos salões à procura de uma coisa rara: imaginação. E aqui cria uma imagem para falar das imagens que vê e parece reatualizar o poema de Baudelaire "A uma passante". O crítico, que tem como obrigação escrever sobre o salão, ao entrar, depara com uma mulher desconhecida e misteriosa que o encanta e o instiga, "aturde-o" é sua palavra. Diz assim:

No átrio, pouco distante do Gladiador, vejo passar a silhueta ornamental duma esbelta senhora, encantadoramente cingida por um costume-tailleur cor de musgo. Num gesto rápido em que a elegância se confunde com a prática, a sua estreita e fina destra, em pelica branca arrebanha a saia. Descubro a linha de escorço dum borzeguim de verniz. Ela galga os degraus. Ao enviesar no lanço esquerdo em frente ao nicho apanho-lhe o perfil de relance. É claro. Tem a pupila negra. Negros the são os cabelos. [... $]^{2}$

E é buscando essa figura que desaparece e reaparece entre os quadros que ele vai descrevendo o que vê até que ela se vai. Isso que não encontra é personificado na desconhecida que passa e que ele vislumbra, mas não chega a conhecer. Há um ritmo no texto que alterna frases curtas, que dão a rapidez do olhar de relance, com outras longas, minuciosas na descrição da figura. Incorpora um diálogo com um espectador que não entende nada do que vê e ironiza certas paisagens: as marinhazinhas com barquinhos. Quando revê a mulher, depois de falar de alguns quadros fica "desatinado, sem pensar, sem saber o que fazer", passa para as esculturas e critica a política das encomendas. Lembra Schubert e destaca as telas de Visconti e Roberto Mendes. O que se passa entre ele e a desconhecida alegoriza a relação com a arte e a representação - a surpresa e o aturdimento que a desconhecida lhe causa, o aproximar-se e o afastar-se e depois a fuga, a impossibilidade de alcançá-la. Seu desejo pela figura que passa por entre os quadros e traz a dimensão do desconhecido e do inquietante e do não representável é que lhe permite uma reflexão sobre esses quadros.

Segundo Didi-Huberman, a imagem é sempre perda, ela não apreende uma totalidade e sua construção se faz como o jogo do Fort-da que Freud vê na criança, elaborando a perda, a ausência da mãe. Na pintura o pintor entra com seu corpo, diz Merleau-Ponty, citando Valéry, corpo que é entrelaçado de visão e movimento, a crítica

2. Id. 
se faz também com esse pensamento do olhar em que o corpo é vidente e visível, captado no tecido do mundo. A pintura celebra a visibilidade como enigma. Diz MerleauPonty: "Qualidade, luz, corpo, profundidade que estão aí diante de nós, aí só estão porque despertaram um eco em nosso corpo, porque este lhes deu acolhida".

Devolver a solução à condição de enigma, diz Karl Krauss, citado por Agamben em Image et mémoire. Isso saberiam fazer o narrador, o pintor e o poeta. A crítica de Gonzaga Duque sugere que a crítica também é lugar de emergência, de uma imaginação produtora que acolhe o paradoxo e o enigma. Sua crítica se constrói como a imagem, no mesmo jogo que elabora uma perda.

Como trabalha com ideias estéticas, suas imagens mostram o limite dos conceitos ou inserem imagens nos conceitos. Mostram a movência singular da crítica. Se o juízo estético é reflexivo e não determinante ou cognitivo, há uma possibilidade infinita de desdobramento. Há uma consciência dos limites do conceito hoje. A ordem epistemológica moderna converte o mundo em um mecanismo a ser controlado pelo sujeito do conhecimento. De texto decifrável, o mundo passa a ser objeto observável, sem sentido. Com as imagens banalizadas pelos meios de comunicação, a forma estética se torna forma difícil, forma incerta até o mais íntimo de sua textura. A experiência poética é sempre um reencontro da mais íntima alteridade, um sair de si na direção do outro. A crítica de Gonzaga Duque já tem esse teor, talvez porque ficcionista, próximo dos poetas simbolistas, que são críticos do racionalismo progressista que marca o naturalismo; como neorromânticos, muitas de suas questões e propostas são continuadas pelos surrealistas. Assim marcam uma dissidência quanto ao modelo moderno que se impunha, embora modernizar fosse também seu desejo. No entanto, abrem questões que não serão incorporadas pelo modernismo hegemônico. A tentativa de transformar o país num Estado-Nação moderno, isto é, num Estado planejador, comportava planejar, ou seja, definir a diferença entre ordem e caos, separar o próprio do impróprio, legitimar um padrão às expensas de todos os outros. A construção da ordem significa promover a uniformidade, o que caracteriza a sociedade moderna: uma intolerância radical de quaisquer formas de vida diferentes, as diferenças são vistas como ignorância, superstição ou atraso.

Em outro texto de Contemporâneos, "O salão de 1906", Gonzaga Duque cria um personagem, Policarpo, que o acompanha na visita ao salão e num diálogo com ele vai discutindo o que vê. O diálogo lembra o ensaio de Oscar Wilde, "O crítico como um artista”, em que discussões teóricas importantes são travadas num diálogo fictício entre dois personagens, Gilbert e Ernst, que depois vão para as ruas, como no texto de Gonzaga Duque, que termina assim: 
Agora à vida

À vida - confirmou Policarpo.

E saímos para o ar livre das ruas.

Mas, neste, diferentemente do texto de Wilde, Policarpo e o crítico concordam geralmente, um ecoando o outro, embora o amigo fictício seja mais espontâneo. Diante de um quadro de Artur Lucas, o texto diz:

Policarpo, comovido, sacode-me o braço:

- Bem, que dizes?

— É um artista, amigo Policarpo, é um artista que aqui está, para gozo nosso e honra da pátria.

Às vezes ironiza. Sobre Julieta França, a escultora, põe as palavras na boca de Policarpo, para dizer que lhe falta interpretação, que deveria pensar, refletir, estudar mais seu assunto.

Ao tentar recortar o início da crítica de arte no Brasil, deparei com a questão: se no modernismo dos anos 20 ou se na década de 50. Antecipei esse recorte descobrindo Gonzaga Duque, um escritor simbolista, atuante entre 1886 e 1911, como o primeiro crítico moderno das artes plásticas do país. São seus $A$ arte brasileira e o romance Mocidade morta que mostram um crítico ficcionista, inaugurando aqui também um veio de críticos poetas. Gonzaga Duque trabalha esse encontro entre palavra e imagem, com afinidades com Diderot, Zola, Baudelaire, Huysmans e Fromentin, críticos e ficcionistas e referências suas. Seus textos de crítica são marcados por imagens que fazem pensar sobre uma crítica de arte como tradução de linguagens que escapa aos limites do conceito, articulando-se em imagens que contêm ideias, um pensamento que inclui a sensibilidade e a sensualidade. Como se a reflexão se desdobrasse nessas passagens de uma linguagem a outra, abrindo outras possibilidades de articulações de sentido. Há um impulso ficcional nessa crítica e uma aguda consciência da linguagem que faz com que às vezes interrompa o texto com uma reflexão sobre as palavras que usa. Por exemplo, no Salão de 1904, pensa sobre o uso da palavra senhoras num parêntese, ao se referir às mulheres pintoras; diz:

As senhoras... (Como eu implico com esta palavra, neste particular! É fofa, tola, convencional. Tem alguma coisa de pieguice e muito do ranço da burguesia aristocratizada. 
Porque não dizer mulheres, que é uma palavra dignificadora?...) As senhoras - vá lá, repetirei - que se exibem na paisagem e outros assuntos a óleos devem ter desvanecido seus mestres, porque, sinceramente, merecem elogios! (p. 108)

O que remete para o artigo sobre o Salão de 1907, em que termina dizendo que uma das revelações do salão é o grande número de pintoras que ali se exibiu e algumas com real merecimento, o que o faz perguntar-se: "A nossa arte de amanhã será uma das conquistas do feminismo?".

Argan, em texto sobre Murilo Mendes, diz que para ele a linguagem da crítica era precisamente o nexo entre as duas versões da imagem, a visual e a verbal, numa prosa que resultava estranhamente rarefeita e algo vagarosa. O que me parece que se inaugura com Gonzaga Duque e continua em alguns críticos poetas, ou melhor, poetas que se dedicam à crítica de arte mais como amadores como os textos de Murilo Mendes, e de outros que ainda estou levantando, seria uma singularidade de olhar, de apreensão e apreciação que se dá numa linguagem crítica, que incorpora a imagem. Uma subjetividade na qual o inconsciente joga sua sombra, um imaginário forte, um impulso ficcional vão articular uma crítica ensaística, que se coloca quase como um gênero. Nela a linguagem se adensa e intensifica. A crítica de Murilo tem sido objeto de estudos. Entre as crônicas de Manuel Bandeira há uma sobre Lasar Segall que pode ser considerada também um texto de crítica. E várias outras também sobre a arquitetura de Le Corbusier, por exemplo.

E primeiro Gonzaga Duque, isso vai permitir que inaugure a moderna crítica no país, criando a impressão, com seu romance, os ensaios e o livro de história da arte, de que já haveria um sistema organizado de artes plásticas, o que o levava a interferir num meio que isolava esses artistas (como Castagneto, sobre quem escreveu), tensionados entre incursões mais arrojadas nas suas questões e o modelo acadêmico instituído.

A força poética dessa crítica, que escapa ao rigor do método e ao fechamento do conceito, mais provoca o pensamento do que o torna claro. Ela permitiria também, articulando a memória, rearticular a história ou mesmo criar uma história, como faz Gonzaga Duque em A arte brasileira e Revoluções brasileiras.

Outro lugar onde essas relações vão se articulando são também as revistas do grupo que estão se desfazendo em pó nas bibliotecas. Elas trazem desenho, caricatura e fotografia junto com textos literários. Além de mostrar os textos que estão circulando, como, por exemplo, passagens de Novalis e Mallarmé, permitem recuperar reminiscências que rearticulam nossas noções de Moderno e Modernismo, ao mesmo tempo 
que articulam uma arqueologia da cidade. Figuras e questões saem do simbolismo e fazem esse modernismo carioca. Um intelectual ativo nesse meio das revistas, além de Gonzaga Duque, que funda Pierrot, Mercúrio e Fon-fon e escreve em Kosmos, é Álvaro Moreyra, que começa em Fon-fon e funda Paratodos. Formando uma boêmia dissidente, não aderiram a um modernismo futurista e construtivista, que acreditava na industrialização: para eles é a rememoração de uma experiência perdida que permite opor-se à catástrofe moderna, que lida apenas com a experiência imediata. O novo para eles é sempre o bizarro, o enigmático, o ainda-não consciente que a arte tornaria visível.

Merleau Ponty, em $O$ olho e o espírito, fala do pensamento do pintor que se opõe ao pensamento cartesiano. Cita Max Ernst e fala de uma visão que se faz em nós como Rimbaud na "Carta do vidente" diz que algo se pensa nele. Há no centro desse pensamento da visão um mistério de passividade. Merleau Ponty afirma que a pintura baralha nossas categorias, ao desdobrar o seu universo onírico de essências carnais, de semelhanças eficazes, de mudas significações.

Didi-Hubermann, falando de Carl Einstein (em Devant le temps), diz que é preciso trabalhar a imagem com conceitos insuspeitados. Criar novas formas de saber ao contato com as novas formas de arte. A crítica é também lugar de criação. Inventar formas também no domínio do conhecimento é colocar em questão a realidade e seu próprio eu - criar sem cessar uma realidade nova, como faz a arte.

Agora falarei de Nestor Victor, que também sempre me surpreende. Escreveu sobre Gonzaga Duque em 1929, quando saiu Contemporâneos, e diz que havia nele "algo de um revel, de um irreverente ao academicismo, aliás, como em todo simbolista que se prezasse". Seus livros de crítica, como A crítica de ontem, Cartas à gente nova e outros, estão reunidos nos três volumes publicados pela Casa de Rui Barbosa. Trabalhei seu ensaio Paris, livro que compara o Rio de Janeiro com Paris com imagens de lá e de cá, num momento em que os cafés eram substituídos pelo modelo americano. Crítico simbolista, Nestor Victor morou na capital francesa, de 1901 a 1905. Escrito em 1911, o livro tensiona com a narrativa de viagem, nele se compara a capital francesa com a capital brasileira, costumes, mulheres, espetáculos, com uma visão crítica das duas cidades. Desde Montaigne, criador do gênero, o ensaio seria uma viagem de autoprospecção, que aparece sob o impacto das descobertas que mobilizam o imaginário europeu. A leitura de Paris deixa ver, do lado de cá, o escritor brasileiro, mesmo antes das vanguardas, como um viajante, que desenvolve um pensamento sobre o país, na forma do ensaio, gênero que acolhe o conflito, a proble- 
matização e o inacabamento. Logo nos três primeiros capítulos, já pelos títulos Nestor Victor se revela um leitor de Baudelaire e Poe: "A rua", "Quem passa", "A alma da multidão". Começa com as imagens da multidão nas duas cidades e vem desenhando as diferenças, à medida que aparecem. Seu método é mostrar, por contraste, o que se vai configurando no decorrer do texto. Assume o ensaio como um autorretrato, isto é, faz de si o palco da experiência intelectual. Diz: "É preciso haver-se estado na Europa para vermos que lados imprevistos do nosso ser ali se revelam, generalidades e defeitos de que quase nem nos apercebemos, vivendo no nosso próprio meio". ${ }^{3}$

Em capítulos que valem como fragmentos, suficientes em si mesmos, não tem a pretensão de esgotar o assunto, mas criar imagens dos dois lados. Começa com a rua e fala da diferença de luz, nossos horizontes luminosos contrastam com a sombra europeia. A Avenida Central lhe parece uma enorme caixa de brinquedos em que há de tudo. Diz que somos de uma ensandecida imaginação, sem medida e sem freio: "Só o novo admiramos. Lá o arquiteto teve de aceitar o que já havia, sabendo tirar disso o melhor partido possível. Aqui, com exceção desta ou daquela rua, fez-se tábua rasa, como se tivesse passado um terremoto na edificação e construiu-se tudo de novo".

Mas sua crítica também surpreende. Acolhe artistas nos seus primeiros livros como Gilka Machado. Se os críticos a chamam de despudorada, ele vê a artista feita, já no primeiro livro. Escreve também sobre Nietzsche, Novalis, Maeterlink e Ibsen, Mallarmé e Whitman, escritores ainda pouco conhecidos aqui na época. Compara Mário de Andrade com Whitman em 1928. Sua compreensão da poesia, como a passagem abaixo mostra, lhe permite, na contramão, entender Cruz e Sousa.

Pode-se dizer que o verso é um instrumento de clarificação dos nossos sentimentos ainda obscuros. O poeta quando compõe está no mesmo caso de quem sonha, e, como este revela às vezes, falando alto a quem o ouça, o que acordado não contará nem a si próprio, também aquele, não raro, confia à traidora e misteriosa rima, que conta ainda mais do que se lhe diz, o que nem ele mesmo imaginara andar-lhe nos recessos d'alma. Assim, a poesia é mais do que confissão: é a integração de nós mesmos, antes de tudo perante nós mesmos, é a incorporação ao consciente daquilo que representamos de realidade ideal. ${ }^{4}$

3. Victor, Nestor. Paris. Rio de Janeiro: Livraria Francisco Alves, 1911.

4. victor, Nestor. Obra crítica. v. 2. Rio de Janeiro: Fundação Casa de Rui Barbosa, 1969, p.81. 
Gonzaga Duque escrevendo entre 1880 e 1911 e Nestor Victor entre 1897 e 1932 marcam essa virada de século, o último já se estendendo ao Modernismo; fazem pensar esse período de fim de século e início de outro como dentro do regime estético. Para Rancière, o regime estético se opõe ao regime representativo e começa já um pouco antes da Revolução francesa. No regime estético das artes abolem-se os gêneros e o interesse muda para o comum e o banal.

Num livro recente, Aisthesis, ${ }^{5}$ Rancière vê em várias cenas da virada do século XIX para o xx uma mutação das formas de experiência sensível, da maneira de perceber e de ser afetado, que propicia reconfigurações da experiência e um modo novo de sensibilidade. Fala de cenas de pensamento que acolhem o até ali impensável. "Pois o pensamento é sempre um pensamento do pensável, um pensamento que modifica o pensável acolhendo o que era impensável." (p. 12). E faz uma contra-história da modernidade artística, incorporando episódios que já deslocam a percepção em cenas de pensamento. Rancière vai de 1764 a 1941, de Théophile Gauthier e Ruskin a James Agee.

E é o que estamos fazendo aqui, encontrando cenas de pensamento nestes autores da virada do século. Num momento em que se comemora de novo 22 como marco da grande ruptura na arte brasileira, estamos na contramão, também insubmissos...

Vera Lins é professora de Literatura comparada da Faculdade de Letras da UFRJ. Reeditou livros de Gonzaga Duque, sobre quem escreveu sua tese de doutorado, Novos Pierrôs, velhos saltimbancos (Eduerj, 1998). Suas publicações mais recentes são O poema em tempos de barbárie e outros ensaios pela Eduerj e Desejo de escrita pela 7letras, ambos em 2013.

5. RANCIÈre, Jacques. Aisthesis: scènes du régime esthétique de l’art. Paris: Éditions Galilée, 2011. 